Research Letters

\title{
A new extraction method of bioflavanoids from poisonous plant (Gratiola Officinalis L.)
}

\author{
Natalya V. Polukonova, Mariya N. Kurchatova, Nikita A. Navolokin, Alla B. Bucharskaya, Natalya A. Durnova, \\ Galina N. Maslyakova
}

Saratov State Medical University n.a. V.I. Razumovsky, Saratov, Russia

Received 25 August 2014, Accepted 08 September 2014

(C) 2014, Polukonova N.V., Kurchatova M.N., Navolokin N.A., Bucharskaya A.B., Durnova N.A., Maslyakova G.N.

C 2014, Russian Open Medical Journal

\begin{abstract}
The way of vegetable raw materials extraction which allows to receive nontoxical composition of biological active agents from poisonous plants such as Gratiola officinalis L. was described. The alkaloids exit changes with the increase of ethyl alcohol percentage (from $15 \%$ to $96 \%$ ). The extract was obtained using $96 \%$ ethanol and did not give positive high quality reaction to the content of alkaloids. The chemical composition with new nontoxical biological active composition of Gratiola officinalis L. extract was investigated. The extract contains a previously unknown plant - bioflavonoid quercetin. The average value of quercetin in this extract using the calibration curve of the standard sample quercetin (98\%) Sigma is $0.66 \%$. In the dry rest of extractive substances (Gratiola officinalis L.) the quantity of quercetin was $350 \mathrm{mkg}$ (obtained from $10 \mathrm{~g}$ of a dry grass) as was established by the method of a liquid chromatography.
\end{abstract}

Keywords: Gratiola officinalis L., hyssop, bioflavonoids, chemical composition, extraction method, quercetin

Cite as Polukonova NV, Kurchatova MN, Navolokin NA, Bucharskaya AB, Durnova NA, Maslyakova GN. A new extraction method of bioflavanoids from poisonous plant (Gratiola Officinalis L.). Russian Open Medical Journal 2014; 3: 0304.

Correspondence to Prof. Galina N. Maslyakova. Address: Saratov State Medical University, 121, Bolshaya Kazachya str., Saratov, 410012, Russia. E-mail: gmaslyakova@yandex.ru

\section{Introduction}

Now biologically active compositions of obtaining methods of raw medicinal plants (with the least side effects and with the maximum positive pharmacological action) are effectively investigated. Perennial plant of the family Scrophulariaceae Gratiola officinalis $L$. is widespread in Eurasia and North America [1]. The plant is poisonous. Pets recognize and does not eat the Gratiola officinalis $\mathrm{L}$. on the pastures, but this plant can get together with hay and cause poisoning; especially horses are sensitive to the Gratiola officinalis L. Quality of the Gratiola officinalis $L$. raw medicinal material is regulated by pharmacopoeial article 42-2358-85. Previously the Gratiola officinalis $L$. grass was a part of Zdrenko composition and was used as a symptomatic treatment of papillomatosis gastritis and as a laxative, anthelminthic, cardiotonic, diuretic and antiseptic remedy. The water infusions and $15 \%$ alcohol tincture of herb ware used [2]. The Gratiola officinalis L. grass extractions have a very high toxicity, so they are used together with mucous decoctions, for internal use with great caution and under compulsory medical supervision [3].

Different extraction methods from the same plant materials can result in a biologically active substance with different chemical composition and properties [4]. Thus the extractive substances remain toxic when receiving an extract from the raw materials Gratiola officinalis L. by extraction with $96 \%$ ethanol or methanol or isopropanol) and chloroform [5], in which chloroform fraction is produced and is used with non-polar compounds, including toxic compounds (alkaloids and glycosides). In addition, this extraction way possesses significant laxative effect, caused by the presence of toxic substances of glycosides and alkaloids and they have an irritanting effect on the intestine, thus its scope is reduced sharply. There are also ways of obtaining water infusions tinctures and alcoholic extracts from Gratiola officinalis L. including the use of different concentrations of ethyl alcohol and chloroform. Etracts from Gratiola officinalis L. contain glycosides - gratiolinum, cucurbitaceous glycoside - elatericid, fatty oil, saponins, apple and betulinic acid, carbohydrates (stagione), terpenoids (elaterizid, deacetelaterinid, cucurbitacin E and I), cardenolides, saponins, flavonoids (lignoside, isolignoside, apigenin, kosmosiin, avrozid, isoavrizid, neoavrozid, isoneoavrozid) and alkaloids $(0.2 \%)$ with yet unknown composition, in different varying proportions, depending on the method of selection [3, 5, 6-9].

In this work we analyze the extract obtained from a new hot previously applied method for Gratiola officinalis L., which allows to obtain non-toxic extractives from poisonous plants. We have already described the positive effects of Gratiola officinalis $L$. on the organism of animals with transplanted liver cancer and at the same time, the negative cytotoxic and cytostatic effects on tumor cells [10-12].

Objective: to describe a method for obtaining a non-toxic extract from the grass of poisonous plants Gratiola officinalis $L$. containing bioflavonoids, and to conduct chemical analysis of this extract. 
Table1. Specific qualitative reactions to bioflavonoids and alkaloids of Gratiola officinalis L. extracts: 1) extract received with 96\% ethyl alcohol, 2) hydroalcoholic extract obtained with $70 \%$ ethyl alcohol, 3) $15 \%$ alcohol tincture, 4) water infusion alcohol solution

\begin{tabular}{ccc} 
Extract & Synod sample \\
\hline 1 & intense red-brown colouring intense red-brown colouring & with aluminium chloride reaction results \\
2 & weak red-brown colouring \\
4 & intensive lemon-yellow colouring \\
\hline
\end{tabular}

\section{Material and methods}

Grass Gratiola officinalis L. was collected on the Volga island near the settlement of Chardym (Saratov region) in June 2011. For the qualitative reactions the extracts were obtained in different ways: with $96 \%$ ethyl alcohol, with $70 \%$ ethanol and $15 \%$ ethyl alcohol and with water infusion of Gratiola officinalis L. grass [13].

To detect the presense of flavonoids the Synod probe was used, the reactions were performed with aluminium chloride and lye to determine the presence of flavonoids, the reactions were carried out with the Wagner-Bouchard reagent, with $1 \%$ solution of picric acid, acid solution of phosphomolybdenum, with silicowolframic acid in the presence of alkaloids [13].

The water infusion, $15 \%$ alcohol tincture and $70 \%$ alcohol tincture were used for comparison with $96 \%$ alcohol extract from Gratiola officinalis L. grass [13].

To determine the chemical composition the extract from Gratiola officinalis $L$. grass obtained with $96 \%$ ethanol was used. The essence of this method consists in the use of high concentrations of ethanol due to relatively lower boiling temperature than water, which contributes to better safety of the flavonoids during the extraction of raw materials [13]. The essence of this method consists in the use of high concentrations of ethanol due to relatively lower boiling temperature than water, which contributes to better safety of the flavonoids during the extraction of raw materials [13]. This extraction method includes cleaning stage from toxic compounds (alkaloids, glycosides and others) by their dissolution in chloroform, futher centrifugation and deliverance of chloroform fraction [14].

Water fraction is dried in a Petri dish, which allows to get a dry residue of targeted products and futher to determine exact concentration and to calculate the exact dosage for the experiments, both in vitro and in vivo, and it allows to keep an extract for a long periods [14].

The study of chemical composition of $96 \%$ alcohol extract of Gratiola officinalis was conducted by chromatography-mass spectrometry method on the chromatography-mass spectrometer Trace GC - Trace DSQ (ThermoFinnigan, USA). Optimal conditions were found for separation mixtures of analyzed substances in the solvent (ethyl alcohol). The mobile phase was helium, 99.995\% purity (flow rate of $1.2 \mathrm{ml} / \mathrm{min}$ ).

Mark chromatographic column: Restek Stabilwax, 30 m, inner diameter of $0.25 \mathrm{~mm}$, thickness phase 0.25 microns (column with a non-polar stationary phase on the basis of polyethylene glycol) was used. Temperature program was at $150^{\circ} \mathrm{C}$ for $10 \mathrm{~min}$, then the heating up to $240^{\circ} \mathrm{C}$ for $10 \mathrm{~min}$. $\mathrm{t}$ injector was $290^{\circ} \mathrm{C}$, $\mathrm{t}$ ion source was $220^{\circ} \mathrm{C}$. The scan was conducted in the interval $45-400 \mathrm{u}$ (Full Scan), Splitless mode. MS Transfer Line $=250^{\circ} \mathrm{C}$. Turning on the filament was in $5 \mathrm{~min}$ after injection of sample of $2 \mu$ l. Library NIST 02 (National Institute of Standards and Technology, USA, Wiley) was used. Recognition of detected compounds was performed by comparing the mass spectra with mass-spectra libraries.
Determination of quercetin amount in $96 \%$ ethanol extract of Gratiola officinalis was performed using liquid chromatography by the standard method for "high performance liquid chromatography" device Stayer UV/VIS (Aquilon Ltd, Russia) in isocratic mode, with spectrophotometric detector [15]. The standard sample of quercetin (98\%, Sigma-Aldrich) was used to the quantitative determination of quercetin. For a quantitative determination of quercetin the standard sample of quercetin (98\%) was used.

The substance was dissolved quantitatively in $5 \mathrm{ml}$ of ethyl alcohol in a Petri dish, and then the mixture was diluted in 10 and 20 times just before the chromatography. The conducted chromatography was carried out on the gradient HPLC - device Stayer UV/VIS (Aquilon Ltd, Russia) in isocratic mode, with spectrophotometric detector. The wavelength was $254 \mathrm{~nm}$. "The center for Collective Use" has developed a method for optimal separation and determination of quercetin in the presence of other flavonoids and alkaloids. The chromatography was carried out in reversed-phase isocratic mode, the mobile phase - the concentration of isopropanol was $30 \%$, bitrate was $700 \mu \mathrm{l} / \mathrm{min}$, the retention time for quercetin was from 7.65 to 7.75 minutes. Column "Phenomenex Luna $5 \mathrm{U}$ C18(2), pore size of $100 \mathrm{A0}$; length was $150 \mathrm{~mm}$ and diameter was $4.60 \mathrm{~mm}$; the size of the sorbent was 5 micron. The sample was diluted in 20 times.

\section{Results and Discussion}

We have carried out high-quality reactions to the presence of bioflavonoids and alkaloids in the extracts of Gratiola officinalis, obtained by different methods (Tables 1 and 2). The intensity of the color quality bioflavonoids reactions was highest in $96 \%$ alcohol extract and minimum intensity was observed in aqueous infusions (minimum content of flavonoids) (Table 1). The appearance of the precipitate and the most color intensity reaction to alkaloids was from aqueous infusion of Gratiola officinalis (indicates the presence of alkaloids) and the lowest with $96 \%$ alcoholic extract of Gratiola officinalis (no alkaloids) (Tables 1 and 2). Alkaloids were not detected in 96\% ethanol extract of Gratiola officinalis L.

Two methods were analized - our method of extracting from Gratiola officinalis by $96 \%$ alcohol [14] and the closest to it the method for preparing an extract from Gratiola officinalis $L$. by the extracting of crushed material by $96 \%$ ethanol or methanol or isopropanol), removal of the solvent under vacuum at a temperature of $80^{\circ} \mathrm{C}$, heating the residue with the solvent (cyclic or aromatic) or chlorinated solvents (benzene, toluene, xylene, chloroformom), removal of the solvent under vacuum, dissoluting the purified extract in water at a temperature of $55-130^{\circ} \mathrm{C}$, cooling, processing ethyl ketone, filtering, removal of the solvent by distillation under vacuum [5] (Table 3). The toxicity of the extract of Gratiola officinalis L., obtained by this way, according to the authors of the patent, is reduced, but the extract has a strong laxative and antispasmodic action [5]. 
Table 2. Qualitative reaction results to alkaloids contained in extracts from Gratiola officinalis L.: 1) extract received with $96 \%$ ethyl alcohol, 2) hydroalcoholic extract obtained with $70 \%$ ethyl alcohol, 3) $15 \%$ alcohol tincture, 4) water infusion alcohol solution

\begin{tabular}{|c|c|c|c|c|}
\hline \multirow[t]{2}{*}{ Extract } & \multicolumn{4}{|c|}{ Qualitative reaction results } \\
\hline & Wagner-Buchard reagent & Picric acid solution $1 \%$ & The acid solution phosphomolybdenum & Silicowolframic acid \\
\hline 1 & \multirow{4}{*}{ brown sludge loss } & \multirow{4}{*}{$\begin{array}{c}\text { solution yellowing and } \\
\text { turbidity }\end{array}$} & there are no changes & \\
\hline 2 & & & there are no changes & \\
\hline 3 & & & $\begin{array}{l}\text { solution yellowing goes green with time solution } \\
\text { yellowing goes green with time }\end{array}$ & solution lightening \\
\hline 4 & & & $\begin{array}{l}\text { solution intense yellow coloration goes green } \\
\text { with time }\end{array}$ & solution intensive lightening \\
\hline
\end{tabular}

Table 3. Comparative analysis of the proposed and opposed extraction methods

\begin{tabular}{|c|c|c|}
\hline Stages & Opposed method & Proposed method \\
\hline 1 & \multicolumn{2}{|c|}{ Raw material grinding } \\
\hline 2 & Extraction by boiling in $96 \%$ alcohol & $\begin{array}{l}\text { Extraction by boiling in } 96 \% \text { alcohol on the water bath for } 14-15 \text { minutes. } \\
\text { Filtering of the obtained extract and carefully pressed the extracted raw } \\
\text { materials for removal of large ballast particles. }\end{array}$ \\
\hline 3 & $\begin{array}{l}\text { Evaporation extract method of distillation or distillation in } \\
\text { vacuum. }\end{array}$ & $\begin{array}{l}\text { Evaporation to dryness in a thermostat at the temperature not above } 55 \\
00^{\circ} \mathrm{C}\end{array}$ \\
\hline 4 & $\begin{array}{l}\text { The dissolution of the obtained extract aromatic or acyclic } \\
\text { hydrocarbons or chlorinated solvents with the subsequent } \\
\text { boiling of this solution. }\end{array}$ & $\begin{array}{l}\text { Add distilled water to evaporated extract at } 40-50{ }^{0} \mathrm{C} \text { ( } 4 / 5 \text { part of the total } \\
\text { volume), careful dissolving of the dry extract. Adding chloroform }(1 / 5 \text { part of } \\
\text { the total volume) to aqueous solution of dry extract for dissolution of toxic } \\
\text { compounds (alkaloids, glycosides). All manipulations are carried out at a } \\
\text { temperature of no higher than } 55-60^{\circ} \mathrm{C} \text {. }\end{array}$ \\
\hline 5 & - & $\begin{array}{l}\text { Centrifugation of dry extract water-chloroform solution for } 15 \text { minutes at a } \\
\text { speed of } 1500 \mathrm{rpm} \text {, it allows to receive the most complete separation of } \\
\text { target products water faction and toxic products chloroform fraction } \\
\text { containing non-polar contaminants, such as, chlorophyll and other, as well as } \\
\text { the alkaloids and glycosides }\end{array}$ \\
\hline 6 & $\begin{array}{l}\text { The solvent (chloroform) from hot solution at a temperature of } \\
80^{\circ} \mathrm{C} \text { using vacuum. Extraction with alkanols from } 4 \text { to } 5 \text { carbon } \\
\text { atoms, or dialkyl ketone, having only } 4 \text { to } 6 \text { carbon atoms }\end{array}$ & $\begin{array}{l}\text { Remove chloroform fraction with non-polar substances (chlorophyll) and } \\
\text { others, as well as the alkaloids and glycosides. All long manipulations are } \\
\text { carried out at a temperature of no higher than } 55-60^{\circ} \mathrm{C} .\end{array}$ \\
\hline 7 & $\begin{array}{l}\text { Department of organic phase from water by decantation or } \\
\text { vacuum, further organic phase was used and the solvent from } \\
\text { the organic phase entirely, respectively distillation, leaving the } \\
\text { sediment. }\end{array}$ & The aqueous phase is used in further \\
\hline 8 & $\begin{array}{l}\text { Liquid residue contains alkaloids and glycosides and does not } \\
\text { contain flavonoids. }\end{array}$ & $\begin{array}{l}\text { Drying of water fraction in a Petri dish allows obtaining the target products } \\
\text { dry residue }\end{array}$ \\
\hline
\end{tabular}

The most significant differences between the compared methods for the preparation of extracts are in three steps: "4", "6" and "7"(Table 3). In step "4" the preparation of the extract is not only the addition of solvent, but also by boiling of obtained solution during unspecified time, which means that boiling does not affect the output of target products. While in our method the extraction by boiling in $96 \%$ ethanol was conducted strictly 15 min (because the destruction of target products occurs at a prolonged boiling).

In steps "6"and "7" of opposed method one chloroform was removed by evaporation without removal of alkaloids and glycosides and further the organic fraction contains these toxic compounds and does not contain flavonoids, because most of them were destroyed in the early steps. While, as in our method alkaloids and glycosides containing in the chloroform fraction were removed.

As a result, we have obtained an extract of a dry residue that allows to estimate its concentration, and by opposite method, alcohols and esters are added, the output liquid extract is obtained but it is difficult to determine its concentration.

All these differences in extraction way affect the final product, and it is confirmed by their different biological properties. Although the opposite method indicated the reduced toxicity of extract, its lethal dosage 50 (LD50) was $600 \mathrm{mg} / \mathrm{kg}$ at peroral administration in rats [7], and the extract obtained by our method in concentration of $1663 \mathrm{mg} / \mathrm{kg}$ was not cause the death of any animals, even at more bioavailable intraperitoneal introduction $[5,11]$.

The above indicates a much higher toxicity of the extract obtained opposable method and low toxicity of the extract obtained by our method. Therefore, extracts the compared methods represent different biological active compositions with different classes of toxicity [5, 10-12].

In addition to the different classes of toxicity, compared biologically active compositions have a different effect. Thus, the cited extract has a strong laxative effect [5], which has a decoction of Gratiola officinalis L., which is due to the toxic substances (alkaloids and glycosides). It has an irritating effect to the intenstine and has a general beneficial effect to animal organism, in contrast to the extract obtained by our method [5, 10-12].

The organic substances were selected from the extract of Gratiola officinalis $L$. received with $96 \%$ ethyl alcohol, the probability of detection corresponds to the "excellent and good compliance"(Table 4, Figure 1).

For the first time the presence of quercetin among flavonoids of the Gratiola officinalis L. was found (Figure 2). The average value of quercetin in this extract is $0.66 \%$, using the calibration curve of standard sample of quercetin (98\%). Quercetin number was $350 \mu \mathrm{g}$ in the dry residue of the extractive substances (derived from $10 \mathrm{~g}$ of dry grass of Gratiola officinalis L.) as established by liquid chromatography. 
Table 4. Substances content in $96 \%$ ethyl alcohol extract from Gratiola officinalis $L$.

\begin{tabular}{ccc}
\hline Substance name & $\begin{array}{c}\text { Molecular } \\
\text { mass }\end{array}$ & $\begin{array}{c}\text { Chemical } \\
\text { formula }\end{array}$ \\
\hline $\begin{array}{c}\text { 4-vinyl-2-methoxyphenol } \\
\text { 4H-Pyran-4-one, 2,3-dyhydro-3,5-dihydroxy- } \\
\text { 6-methyl }\end{array}$ & 150 & $\mathrm{C}_{9} \mathrm{H}_{10} \mathrm{O}_{2}$ \\
2,3-dihydrobenzofuran & 144 & $\mathrm{C}_{6} \mathrm{H}_{8} \mathrm{O}_{4}$ \\
3-Furoic acid & 120 & \\
$\mathrm{C}_{8} \mathrm{H}_{8} \mathrm{O}$ \\
2-Furancarboxaldehyde, 5-(Hydroxymethyl), & 112 & $\mathrm{C}_{5} \mathrm{H}_{4} \mathrm{O}_{3}$ \\
Ethyl- $\alpha$-d-riboside & 126 & $\mathrm{C}_{6} \mathrm{H}_{6} \mathrm{O}_{3}$ \\
4-propylphenol & 178 & $\mathrm{C}_{7} \mathrm{H}_{14} \mathrm{O}_{5}$ \\
Pyrocatechol & 136 & $\mathrm{C}_{9} \mathrm{H}_{12} \mathrm{O}$ \\
L-luxose (pentose) & 110 & $\mathrm{C}_{6} \mathrm{H}_{6} \mathrm{O}_{2}$ \\
6-Deoxyhexose L-galactose, 6-deoxy & 150 & $\mathrm{C}_{5} \mathrm{H}_{10} \mathrm{O}_{5}$ \\
4-Hydroxy-3-methoxyphenylethyl alcohol & 164 & $\mathrm{C}_{6} \mathrm{H}_{12} \mathrm{O}_{5}$ \\
Hexadecanoic Acid (Palmitic Acid) & 168 & $\mathrm{C}_{9} \mathrm{H}_{12} \mathrm{O}_{3}$ \\
Homovanillic acid & 256 & $\mathrm{C}_{16} \mathrm{H}_{32} \mathrm{O}_{2}$ \\
D-allose & 182 & $\mathrm{C}_{9} \mathrm{H}_{10} \mathrm{O}_{4}$ \\
d-Mannitol, 1,4-anhydro & 180 & $\mathrm{C}_{6} \mathrm{H}_{12} \mathrm{O}_{6}$ \\
Benzoic Acid Retardex & 164 & $\mathrm{C}_{6} \mathrm{H}_{12} \mathrm{O}_{5}$ \\
Quercetin & 122 & $\mathrm{C}_{7} \mathrm{H}_{6} \mathrm{O}_{2}$ \\
& 302.2 & $\mathrm{C}_{15} \mathrm{H}_{10} \mathrm{O}_{7}$ \\
\hline
\end{tabular}

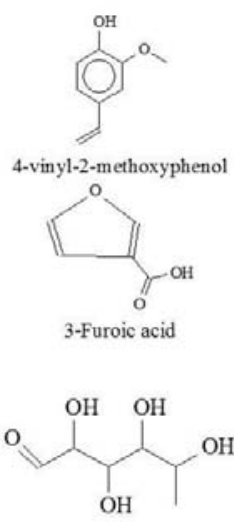

6-Deoxyhexose L-galactose, 6-deoxy

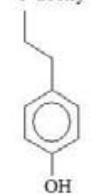

4-propylphenol

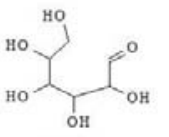

-allose

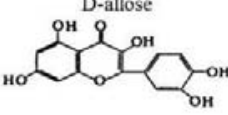

Quercetin
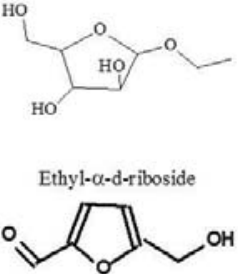

2-Furancarboxaldehyde, 5 (Hydroxymethyl)

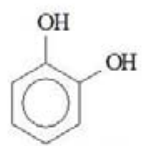

Pyrocatechol

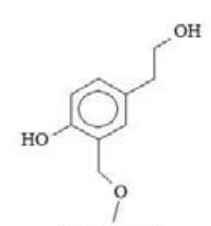

4-Hydroxy-3-

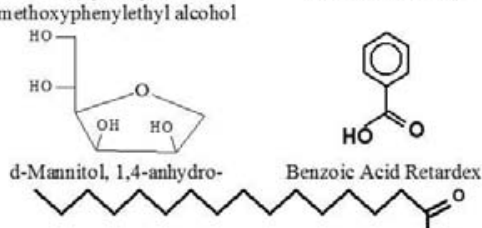

-Mannitol, 1,4-anhydro-<smiles>c1ccc2c(c1)CCO2</smiles>

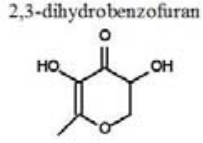

4H-Pyran-4-one, 2,3dyhydro-3,5-dihydroxy-6methyl

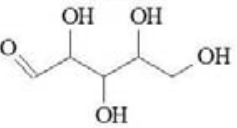

L-luxose (pentose)

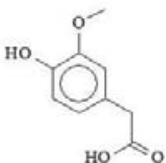

Homovanillic acid

$\widehat{Y}_{\mathrm{H}}^{0}$

Hexadecanoic Acid (Palmitic Acid)
Figure 1. Substances formula of extract from Gratiola officinalis $L$.

\section{Conclusion}

As a result, we have developed a new a method for preparing a dry extract from the grass of Gratiola officinalis L., which is rich in bioflavonoids. As a result, we have developed a method for preparing a dry extract of the herb of Gratiola officinalis L. containing a new, not previously known biologically active composition for this plant.

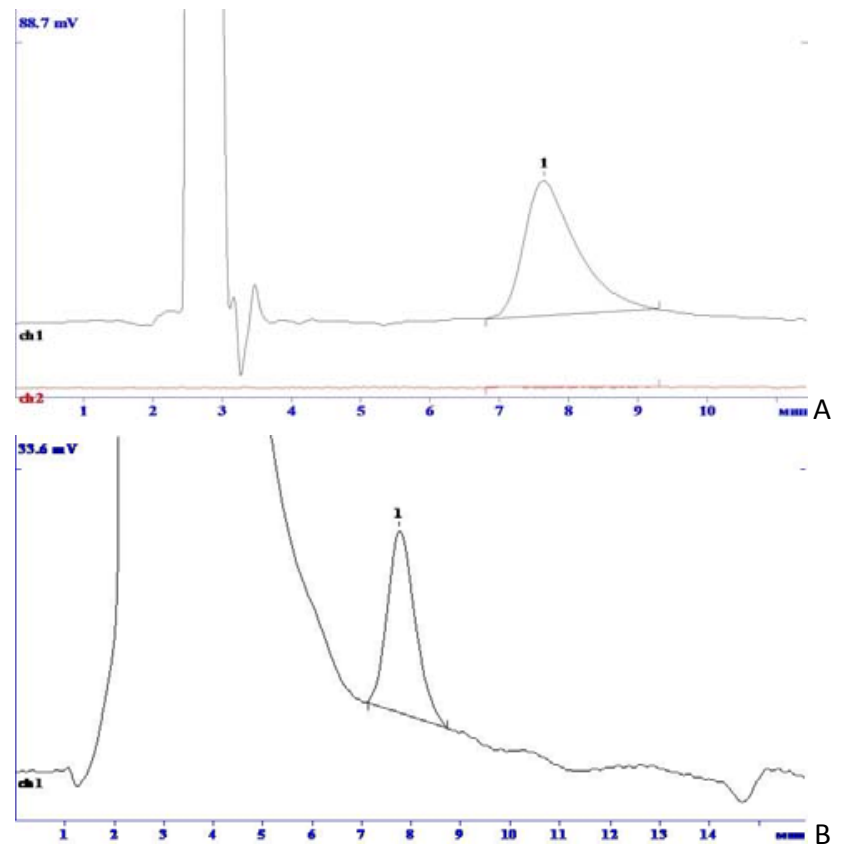

Figure 2. Chromatograms: A - test solution (the sample is diluted in $\mathbf{2 0}$ times); B - quercetin model solution, at a concentration of $10 \mathrm{mg} / \mathrm{ml}$.

New composition comprises an amount of flavonoids, including and quercetin and devoid of toxic compounds - alkaloid glycosides as evidenced by the fact that even high dosages of the extract obtained by us does not cause blue lips, asthma, heart failure in rats [12, 16-19].

Furthermore, we obtained extract which has new properties, in particular antioxidant, anti-tumor and other [5, 10-12]. The extract has no side effects typical for other extracts such as laxative, emetic, antispasmodic, diuretic and digitalis similar effect on the heart.

Our extraction method can be recommended for further study of its biological properties of Gratiola officinalis L. and other medicinal herbs.

Conflict of interest: none declared.

\section{References}

1. Mashkovsky PM, Babayan EA, Abolmasova A, Bulaev VM, Severtsev SD, Tentsova Al. State Pharmacopoeia of the Union of Soviet Socialist republics. 2 edition. Issue 2. Moscow: Medicine, 1989; 400 p. Russian

2. http://www.fito-terapevt.ru/gratiola-officinalis

3. http://www.travolekar.ru/articles.php

4. Ponomarev VD. Extraction of medicinal raw material. Moscow: Medicine, 1976; 186 p. Russian

5. Patent 1063118 (A) Great Britain, MPK7 A61K36/00 A61K36/80. Plant extract / MEN JEAN LE.; the applicant and the patentee ROGER BELLON. №GB19640048825; Appl. 01.12.1964; publ. 30.03.1967.

6. Pezzuto D, Darrick SH, Kim L. Methods of manufacturing betulinic acid. US patent 5.804.575. 1997.

7. Ruzicka L, Lamberton AH, Christe Ruzicka CW. Synthetic approach to betulinic acid. Helv Chim Acta 1938; 21: 1706-1717.

8. Kurkin VA. Pharmacognosy: a Textbook for students of pharmaceutical institutes. Samara, Russia: LLC Etching, Samara state medical University, 2004. Russian 
9. Alefirov AN. Herbal medicine against cancer. Series: Medicine of the XXI century. St. Petersburg: Publishing House Krylov, 2010; 240 p. Russian

10. Polukonova NV, Merkulova HE, Durnova N, Romanteeva JV, Borodulin VG. Study of antioxidant activity of the extract of Hauran drug in rats with inoculated tumors of the liver PC-1. In: Abstracts of scientific conference "Biologically active substances: fundamental and applied problems of production and application" (Novy Svet, Crimea, Ukraine 23-28 may 2011). Kiev, 2011: 585. Russian

11. Navolokin NA, Pavlova AV. Morphological changes in muscles, laboratory rats and determination of toxicity with the introduction of the extract of Gratiola Officinalis L. Bulletin of Medical Internet Conferences 2012; 2(2): 82. Russian

12. Navolokin NA, Polukonova NV, Maslyakova GN, Bucharskaya AB, Durnova NA. Effect of extracts of Gratiola officinalis and Zea mays on the tumor and the morphology of the internal organs of rats with trasplanted liver cancer. Russian Open Medical Journal 2012; 1(2): 0203.

13. The state Pharmacopoeia of the Russian Federation. Moscow, Russia: Scientific center of medical products, 2008; 704 p. Russian

14. Polukonova NV, Navolokin NA, Durnova N, Maslyakova GN, Bucharskaya AB. The method of obtaining of a dry extract of the vegetable raw material, possessing biological activity. Patent (rus) №2482863.

15. Zolotov YA. Analytical chemistry: fragments of paintings. Moscow: Institute of Geochemistry RAS, 1999; 144 p. Russian

16. Baitman TP, Navolokin NA. Effects of extract gratiola on laboratory animals transplanted with sarcoma S-45. Bulletin of Medical Internet Conferences 2013; 3(2): 374. Russian

17. Polukonova NV, Durnova NA, Kurchatova MN, Navolokin NA, Golikov AG. Chemical analysis of the new biological active composition from Gratiola officinalis L. Chemistry of Plant Raw Materials 2013; 4: 165173. Russian

18. Navolokin NA, Polukonova NV, Maslyakova GN, Bucharskaya AB, Durnova NA. Internal organs morphology and tumors in laboratory rats with transplanted liver cancer PC-1 by oral intoduction containing extract of Gratiola (Gratiola Officinalis L.) and Anthocyan Maize (Zea Mays L.). Saratov Journal of Medical Scientific Research 2013; 9(2): 213-220. Russian

19. Navolokin NA, Polukonova NV, Maslyakov GN, Skvortsova VV, Batman TP, Bucharskaya AB, Durnova N. Antitumor activity of plant extracts containing bioflavonoids. Russian Biotherapeutic Journal 2013; 12(2): 59-59a. Russian

\section{Authors:}

Natalya V. Polukonova - D.Sc., Professor, Department of General Biology, Botany and Pharmacognosy, Saratov State Medical University n.a. V.I. Razumovsky, Saratov, Russia;

Mariya N. Kurchatova - Graduate student, Department of General Biology, Botany and Pharmacognosy, Saratov State Medical University n.a. V.I. Razumovsky, Saratov, Russia;

Nikita A. Navolokin - Graduate student, Department of Pathological Anatomy, Saratov State Medical University n.a. V.I. Razumovsky, Saratov, Russia;

Alla B. Bucharskaya - PhD, Head of Center of Collective Use, Saratov State Medical University n.a. V.I. Razumovsky, Saratov, Russia;

Natalya A. Durnova - D.Sc., Professor, Head of Department of General Biology, Botany and Pharmacognosy, Saratov State Medical University n.a. V.I. Razumovsky, Saratov, Russia;

Galina N. Maslyakova - MD, D.Sc., Professor, Head of Department of Pathological Anatomy, Saratov State Medical University n.a. V.I. Razumovsky, Saratov, Russia. 